\title{
RBC Histogram as Supplementary Diagnostic Tool with Peripheral Smear Examination in Evaluating Anaemia
}

\author{
Byna Syam Sundara Rao*, Vissa Shanthi, Nandam Mohan Rao, Bhavana Grandhi, Vijayalakshmi Muramreddy, Sirasala Praveena \\ Dept of pathology, Narayana medical college, Nellore (India)
}

\begin{abstract}
Background: Red blood cell(RBC) histogram provide an idea about morphological changes of red blood cells in hematological disorders. Peripheral smear examination findings are usually correlated with complete blood cell counts by automated analyzer. To known the utility and advantage of red cell histogram and correlation of microscopic examination of peripheral smear with automated histogram pattern.
\end{abstract}

Methods: Blood sample was collected from 220 anemia patients in ethylene diamine tetra acetic acid (EDTA) tubes for peripheral smear examination and ran in Beckman coulter LH 780 automated hematology analyzer for obtaining histogram, complete blood count includes hemoglobin, total leucocyte count, Platelet count, red blood cell indices and red cell distribution width. This study was undertaken for a period of one month of November 2016 in department of pathology, central laboratory, narayana medical college \& hospital, Nellore.

Results: This study of histograms of 220 different types of anemia consisted predominantly females 154 (70\%), and males $64(30 \%)$. Maximum cases of anemia were noted in 30-40 years of age range. Microcytic hypo chromic anemia was the most common (63.63\%) followed by normocytic normochromic anemia (19.4\%), macrocytic hypochromic anemia (2.2\%), dimorphic anemia (12.72\%) and pancytopenia $(1.8 \%)$.

Left shifted curve and broad base mostly seen in microcytic anemia, right shift curve seen in macrocytic anemia and bimodal peak mostly seen in dimorphic anemia.

Conclusion: Histogram can be used as an important screening test for hematology and can become a new parameter in the diagnosis of anemia though peripheral examination remains the definitive diagnostic test for evaluation.

Keywords: Histogram, RBC, Anemia, Peripheral Smear

\section{Introduction}

Evaluation of anemia for diagnosis and management of various red blood cell (RBC)disorders through red blood cell histogram is a vital part. Complete blood count parameters like red cell distribution width (RDW) and mean corpuscular volume (MCV) are useful along with histogram for interpretation of abnormal red blood cell morphology. ${ }^{[1,2]}$ The Normal Red cell distribution curve is a bell shape and curve peak should be within the normal MCV of 80.0-100.0fl. The narrow red cell distribution curve indicates homogenous population of cells and wider redcell distribution curve indicates a heterogenous population of red cell. In megaloblastic anemia where the red blood cells are larger, the histogram curve will shift to right and the curve will move to left if the cells are smaller than normal like in microcytic anemia. After treatment of underlying cause in anemia, the curve should shift toward the normal range. In dimorphic anemia the histogram curve may show multiple peaks due to two distinct red cell populations.After treatment of the cause of an anemia curve should move toward the normal range.Even when
$\mathrm{MCV}$ is normal, RDW is a good indicator of anisocytosis. ${ }^{[3]}$ Higher RDW represents dual population of cells like small cells, some normal size cells, and immature red cells during degenerative response to anemia which are larger than normal. Histogram can be useful for monitoring the reliability of results ofanalyzer, potential causes of results and arriving at the probable diagnosis. ${ }^{[3]}$

\section{Materials and methods}

The data of 220 samples has been taken from the period of November-2016 to December-2016, central laboratory, Narayana General Hospital \& Medical College, Nellore Andhrapradesh, India.

In this Retrospective study, The Red blood cell histograms of all anemic patients visiting the central diagnostic laboratory of Narayana general hospital were analyzed. The Red blood cell histogram correlated with peripheral smear interpretation when the haemoglobin is low. The spectrum of variations in Red blood cell histograms tabulated with types of anemias based on peripheral smear interpretation. 
Complete blood count including haemoglobin, total leucocytes count (TLC), differential leucocytes count(DLC), platelet count and blood indices were obtained by Beckman coulter LH 780 automated analyser along with histogram. To maintain validity of LH 780 Automatic analysis machine quality control was done. Peripheral smear examination was also done. Normally volume of RBCs from $34 \mathrm{fl}$ to $150 \mathrm{fl}$ represents a good cell distribution ideally.

If the graph starts before $34 \mathrm{fl}$ and touches the baseline before $150 \mathrm{fl}$ are considered to be a left shift indicates microerythrocytosis. If the graph starts after $34 \mathrm{fl}$ and touches the base line after $150 \mathrm{fl}$ are considered to be a right shift indicates macro erythrocytosis. If graph starting at $34 \mathrm{fl}$ and ending between 225-250 $\mathrm{fl}$ are considered to be a broad base. If RBCs Populations has two morphologies then the graph will have two peaks representing to their respective morphology and called as dimorphic red cells. If the RBCs population will have single lineage of cells seen, the graph will be constraint and will look like short peak.

Data was analysed using SPSS 22 and P-value was calculated using chi-square $\&$ degree of freedom. $p$ value of 0.05 or less was considered statistically significant.

Inclusion Criteria: All cases of anemia with low haemoglobin. For men anemia is defined as haemoglobin level less than $13.5 \mathrm{gm} / 100 \mathrm{ml}$ and in women as haemoglobin of less than $12.0 \mathrm{gm} / 100 \mathrm{ml}$. Based on peripheral smear interpretation, different types of anemias like normocytic normochromic, microcytic hypochromic, macrocytic, dimorphic and pancytopenia were included in our study.

Exclusion Criteria: Patient having leukocytosis, leukemaiod reaction, leukaemia, parasites and platelet disorders

\section{Results}

In our study of histograms of various types of anemia total 220 cases were studied. This study includes predominantly females $154(70 \%)$ and males $64(30 \%)$. Maximum number of anemia cases were noted in 30-40 years of age range (Table-1).All cases had anemia with hemoglobin less than $12 \mathrm{gm} / \mathrm{dl}$. All these cases consists of Normocytic normochromic anemia, Microcytic hypochromic anemia, dimorphic anemia and pancytopenia were diagnosed by peripheral smear. In our study $43(19.54 \%)$ cases are normocytic normochromic anemia, $140(63.63 \%)$ cases are of microcytic hypochromic anemia, $5(2.2 \%)$ cases are of macrocytic anemia and $28(12.72 \%$ ) cases are of dimorphic anemia. Pancytopenia was seen in $4(1.8 \%)$ cases (Table-2). Our study of 220 cases showed normal curve in $39(17.7 \%)$ cases, left shift in 64(29\%), right shift in $12(5.45 \%)$, Broad base in 83 (37.72), short peak in $6(2.7 \%)$ cases and bimodal in 6(7.27\%) cases (Table-3). In our study in normocytic normochromic anemia, cases shows MCV, Mean corpuscular hemoglobin (MCH), Mean corpuscular hemoglobin concentration (MCHC) and RDW within normal limits with few cases showing mild increase in RDW. In Microcytic hypochromic anemia $\mathrm{MCV}, \mathrm{MCH}$, are less than normal range with normal $\mathrm{MCHC}$ and increased RDW due to ansiopoikilocytosis. In Macrocytic anemia increase in $\mathrm{MCV}, \mathrm{MCH}, \mathrm{RDW}$ with normal $\mathrm{MCHC}$ due to variation in size \& shape of the RBCs.In Dimorphic anemia, MCV, MCH, MCHC were in the normal limits andRDW was increased due to high degree of ansiopoikilocytosis. In pancytopenia only change noticed in red cell indices are increased RDW with normal $\mathrm{MCV}, \mathrm{MCH}$, and $\mathrm{MCHC}$.In our study out of $43(19.54 \%)$ cases of normocytic normochromic anemia, $26(11.8 \%)$ showed normal curve and $17(7.72) \%$ showed broad base curve. Out of $140(63.23 \%)$ cases of microcytic hypochromic anemia 7(3.18\% ) were normal, 60 (27.27\%) showed left shift curve, $60(27.27 \%)$ showed broad base curve, $7(3.18 \%)$ showed bimodal curve histogram. and $6(2.72 \%)$ showed short peak . Out of total $28(12.7 \%)$ cases of dimorphic anemia $9(4) \%$ showed normal curve, $4(1.81 \%)$ showed left curve, right curve $9(4 \%)$, broad base curve $4(1.81 \%)$ and $2(0.9 \%)$ showed bimodal curve. All $5(2.2 \%)$ cases of macrocytic anemia showed right shift curve. All pancytopenia cases were broad base curve (Table-4). P value of $<0.001$ and chi square value 74.28 were considered statistically significant (Table-4).

Table 1: Age \& sex wise distribution of anemia.

\begin{tabular}{|c|c|c|c|c|c|c|}
\hline Age & $\mathbf{1 0 - 2 0}$ & $\mathbf{2 1 - 3 0}$ & $\mathbf{3 1 - 4 0}$ & $\mathbf{4 1 - 5 0}$ & $\mathbf{5 1 - 6 0}$ & Total \\
\hline Total & 10 & 50 & 100 & 40 & 20 & 220 \\
\hline$\%$ & 4.54 & 22.72 & 45.45 & 18.18 & 9.09 & 100 \\
\hline $\mathrm{M}($ Male $)$ & 4 & 15 & 25 & 15 & 5 & 64 \\
\hline $\mathrm{F}$ (Female) & 6 & 35 & 75 & 25 & 15 & 156 \\
\hline $\mathrm{M}: \mathrm{F}$ & $2: 3$ & $1: 2.3$ & $1: 3$ & $1: 1.6$ & $1: 3$ & $1: 2.4$ \\
\hline
\end{tabular}


Table 2: Distribution of cases per types of anemia.

\begin{tabular}{|c|c|}
\hline Types of anemia & Percentage \\
\hline Normocytic & 43 cases $(19.54 \%)$ \\
\hline Microcytic & 140 cases $(63.63 \%)$ \\
\hline Macrocytic & 5 cases $(2.2 \%)$ \\
\hline Dimorphic & 28 cases $(12.72 \%)$ \\
\hline Pancytopenia & 4 cases $(1.8 \%)$ \\
\hline
\end{tabular}

Table 3: Types of histogram abnormality in the study.

\begin{tabular}{|c|c|}
\hline Types of histogram & Percentage \\
\hline Normal curve & $39(17.7 \%)$ \\
\hline Left shift & $64(29.0 \%)$ \\
\hline Right shift & $12(5.45 \%)$ \\
\hline Broad base & $83(37.72 \%)$ \\
\hline Bimodal & $16(7.27 \%)$ \\
\hline Short peak & $6(2.7 \%)$ \\
\hline
\end{tabular}

Table 4: RBC histogram variations in different anemia.

\begin{tabular}{|l|c|c|c|c|c|c|}
\hline & Normal curve & Left shift & Right shift & Broad base & Bimodal & Short peak \\
\hline Normocytic & $26(11.81 \%)$ & - & - & $17(7.72 \%)$ & - & - \\
\hline Microcytic & $7(3.18 \%)$ & $60(27.27 \%)$ & - & $60(27.27 \%)$ & $7(3.18 \%)$ & $6(2.72)$ \\
\hline Macrocytic & - & - & $5(2.27 \%)$ & & - & - \\
\hline Dimorphic & $6(2.72 \%)$ & $4(1.81 \%)$ & $7(3.18 \%)$ & $2(0.90 \%)$ & $9(4.0 \%)$ & - \\
\hline Pancytopenia & - & - & - & $4(6.2 \%)$ & - & - \\
\hline P value - $<.001$ & & & $\begin{array}{c}\text { Chi square } \\
\text { value - } 74.28\end{array}$ & & & \\
\hline
\end{tabular}

Table 5: Comparitive study of anemias based on peripheral smear.

\begin{tabular}{|l|c|c|c|}
\hline Anemias & Sandhya et al Et al & JitendraChavda et al & Out study \\
\hline Normocytic anemia & $17 \%$ & $17.4 \%$ & $19.4 \%$ \\
\hline Microcytic & $61 \%$ & $65 \%$ & $63.63 \%$ \\
\hline Macro etal & $3 \%$ & $3.6 \%$ & $2.2 \%$ \\
\hline Dimorphic & $15 \%$ & $14 \%$ & $12.7 \%$ \\
\hline Pancytopenia & $3 \%$ & - & $1.8 \%$ \\
\hline
\end{tabular}

Table 6: Comparative study of histogram curves in different studies.

\begin{tabular}{|l|c|c|c|}
\hline Histogram & Sandhya et al & Jitendra Chavda et al & Our study \\
\hline Normocytic & $15 \%$ & $19 \%$ & $17.7 \%$ \\
\hline Left shift & $30 \%$ & $27 \%$ & $29.0 \%$ \\
\hline Right shift & $6 \%$ & $07 \%$ & $5.45 \%$ \\
\hline Broad base & $40 \%$ & $38 \%$ & $37.72 \%$ \\
\hline Bimodal & $4 \%$ & $3 \%$ & $7.27 \%$ \\
\hline Short peak & $5 \%$ & $6 \%$ & $2.7 \%$ \\
\hline
\end{tabular}




\section{Discussion}

The RBC histogram is a graphic representation of particle size distribution in automated cell analyser. This is a standard part of complete blood picture. It provides clues in management and diagnosis of various red cell disorders and give information regarding to $\mathrm{RBC}$ parameters like RDW, MCH and MCV. ${ }^{[1,2]}$ Normal curve is symmetrical bell shaped or Gaussian distribution. Normal curve falls within normal MCV range 80-100fl. The RBC histogram in the cell counter displays the cell ranges for $\mathrm{RBC}$ are between $24 \mathrm{fl}$ and $360 \mathrm{fl}$. The instrument counts only those cells with volume sizes between $36 \mathrm{fl}$ to $360 \mathrm{fl}$ as red cells .Those cells counted in the range $24 \mathrm{fl}$ to $36 \mathrm{fl}$ are rejected and not include in the RBC count. Normally below $36 \mathrm{fl}$ size space is clear, but histogram begin above base line indicates presence of small particles like microspherocytes, malaria parasite, platelet clumps, normoblast, elliptocytes, bacteria, etc. ${ }^{[3,4]} \mathrm{RBC}$ histogram follows well known coulter principle of counting and sizing red cells providing the basis for generating the histogram. This method relies on the change in conductance as each cell passes through an aperture. The change in conductance results in an electrical pulse, the amplitude of which is proportional to the cell volume. The y axis represents the number of cells per channel, with each cell being stored in the representing its size ,so that after data is further processed by the computer, and the RBC Curve is smoothed by a moving average technique and displayed on a data management system. WBCs presented in RBC channel and counted with red blood cells. RBC Histogram is affected if WBCs count is more than 50000 cells. The presence of right sided shoulder usually corresponds to reticulocytosis and a trailer of erythrocyte population on the far right of the histogram correlates to red cell agglutination.

In our study out of 220 anemiacases, 43 (19.54\%) of the cases are Normocytic normochromic anemia, 140(63.63\%) of the cases are Microcytic hypochromic anemia, 5 (2.2\%) Cases with macrocytic anemia and $28(12.72 \%)$ cases are dimorphic anemia. Pancytopenia seen in $4(1.8 \%)$ of the cases .Our findings regarding distribution of anemia cases were correlated with sandhya ${ }^{[5]}$ and Chavda $\mathrm{J}^{[6]}$ (Table-5). Our study out of 220 cases showed normal curve39 (17.7\%), left shift 64(29\%), right shift 12 (5.45\%) Broad base 83 (37.72\%), short peak $6(2.7 \%)$ and bimodal 6(7.27\%). Our findings regarding to $\mathrm{RBC}$ histogram were correlated with other studies like sandhya ${ }^{[5]}$ and Chavda $\mathrm{J}^{[6]}$ (Table-6). In normocytic normochromic anemia, the red cell indices like $\mathrm{MCV}, \mathrm{MCH}$ and $\mathrm{MCHC}$ were within the normal limits with some cases showing mild increase indices. The population of the cells would be variable in size. Like some microcytic cells with predominance of normal size cells that results in a higher deviation and hence higher RDW. In our study out of $43(19.54 \%)$ cases of normocytic normochromic anemia, $26(11.8 \%)$ showed normal curve and $17(7.72) \%$ showed broad base curve. These finding were correlated with study carried by Chavda J. ${ }^{[6]}$

In the microcytic hypochromic anemia, $\mathrm{MCHC}$ may be normal but $\mathrm{MCV}$ and $\mathrm{MCH}$ are decreased. $\mathrm{RBC}$ population with low MCV will be shifted toward left. A broad base curve because of high RDW represents anisocytosis. RDW is also increased when there is increase number of smaller cells like in iron deficiency anemia. In present study MCV and MCH were less than normal in microcytic anemia with normal MCHC and increased RDW due to ansiopoikilocytosis as noted in peripheral smear study. Out of $140(63.23 \%)$ cases of microcytic hypochromic anemia $7(3.18 \%)$ were normal, $60(27.27 \%)$ were left shift curve, $60(27.27 \%)$ showed broad base curve, 7 (3.18\%) showed bimodal curve histogram. and 6 ( $2.72 \%)$ showed short peak. .These finding were correlated with study carried out by sandhya ${ }^{[5]}$ and Chavda J. ${ }^{[6]}$ The short peak well correlated with low haemoglobin and red cell count.

In dimorphic anemia the histogram may have 2 or more red cell populations, whereas in dual populations, the histogram has 2 distinct red cell populations. In dimorphic blood picture there may be dual population of microcytic $\&$ normocytic or normocytic \& macrocytic red cells or admixture of small, normal and large cells of different sizes or admixture of patient and donor red cells. In our study in dimorphic anemia, a $\mathrm{MCV}, \mathrm{MCH}$ and $\mathrm{MCHC}$ were normal and increased RDW due to marked ansiopoikilocytosis. The dimorphic RBC showing bimodal curve along with some cases showing left and right shifting of curve. The reason for dimorphic population may be nutrional anemia, recent blood transfusion or response therapy to nutrional anemia. ${ }^{[7]}$ Out of total $28(12.7 \%)$ cases of dimorphic anemia 9(4)\% showed normal curve, 4(1.81\%) showed left curve $04 \%$ showed right curve $9(4 \%)$, broad base curve $4(1.81 \%)$ and $2(0.9 \%)$ showed bimodal curve. These finding were correlated with study carried out by sandhya ${ }^{[5]}$ and Chavda J. ${ }^{6]}$ In macrocytic anemia right shift with broad based curve means low $\mathrm{Hb}$ and macrocytic blood picture. As Causes of macrocytosis vary from benign to malignant, complete approach is essential to determine the etiology ${ }_{\cdot}^{[8,9]}$ Macrocytosis may occur at any age, but it is more prevalent in old age. ${ }^{[10,11,12]}$ In our study macrocytic anemia due to variation in size and shape of the RBC's, increased $\mathrm{MCV}, \mathrm{RDW}, \mathrm{MCH}$ were noted with normal MCHC. All 5 (2.2\%) cases of macrocytic anemia showed right shift curve. This finding was correlated with Sandhya.

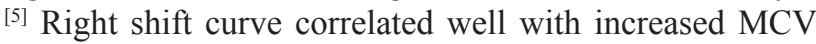
and $\mathrm{MCH}$. All pancytopenia cases were broad base curve and correlated with Sandhya. ${ }^{[5]}$ 
Histogram plays a vital role as working tool in early stage of morphological analysis when combined with concept of normal curve and the knowledge of particular complete blood count parameters like red cell distribution width and red cell indices. Presumption of presence of fragments, microcytichypochromic, macrocytic or dimorphic red cells, and different combinations of cells is possible by observations of outlines of histograms. In addition MCV and MCV provide an idea about distribution of red cell histogram.

\section{Conclusion}

Along with peripheral smear examination, diagnosis ofRBC disorders is supplemented by histogram and they provide guidance regarding RBCS morphology, blood indices and $\mathrm{Hb}$ value. While interpreting microscopic examination of peripherial smear, good idea can be obtained from reviewing histograms. The speed and reliability of analyzers allow time to evaluate abnormal blood smears and correlate with histograms with confidence and efficiency Peripherial smear interpretation was significantly correlated with histogram curve in 220 anemia cases ( $\mathrm{p}$ value $<0.001$, chi square value 74.28). Histogram Changes correlated well with peripheral smear findings in majority of the cases. It is used for screening but not considered diagnostic for any pathological condition.

\section{References}

1. Bessman JD, Gilmer PR Jr, GardnerFH. Improved classification of anemias by MCV and RDW.Am J clin pathol.1983: 80(3):322-6
2. Fossat C, David M, Harle JR, Sainty D, Horschowski N, Verdot JJ, Mongin $\mathrm{M}$ et al. New parameters in erythrocyte counting value of histograms. Archpathol Lab Med. 1987;111(12):1150-54

3. Gulati GL, Hyun BH; The Automated CBC. A current perspective. HematoloncolClin North Am.1994;8(4):593-603

4. Bessman JD. Red bllod cell fragmentation: Improved detection and identification of causes.Am $\mathrm{j}$ clin pathol.1988:90(3):268-73

5. Sandhya I, Muhasin T.P. Study of RBC Histogram in various anemias. Journal of Evolution of Medical and Dental sciences 2014; 3( 74),15521-34

6. Chavda J, Goswami P, Goswami A. RBC histogram as diagnostic tool in anemias. IOSR Journal of Dental and Medical Sciences .2015;14(10), 19-22

7. Benie T. Constantino SH. The Red Cell Histogram and The Dimorphic Red Cell Population .LAB MEDICINE.2011;42(5):300-8

8. Brigden ML. A Systemic approach to macrocytosis: sorting out the causes. Postgrad Med. 1995;97(5):171-84.

9. Kaferle J, Strzoda CE. Evaluation of macrocytosis. Am Fam Physician. 2009; 79(3): 203-8.

10. Argento V, Roylance J, Skudlarska B, et al. Anemia prevalence in a home visit geriatric populations. J Am Med Dir Assoc, 2008;9(6):422-6

11. Younis M, Daugher GA, Dulanto JV, Njeim M, Kuriakose P. Unexplained macrocytosis. South Med J.2013;106(2):121-5

12. McNamee T, Hyland T, Harrington J, Cadogan S, Honari B, Perera K, et al. Haematinic deficiency and macrocytosis in middle-aged and older adults. PLoS One. 2013; 8 (11): e77743

*Corresponding author:

Dr. Byna Syam Sundara Rao, Narayana medical college, Associate Professor, Dept of Pathology, Nellore, Andhra Pradesh 524003 (India).

Phone: +91 09493517944

Email: syam.byna@gmail.com

Date of Submission : 11.04.2017

Date of Acceptance : 01.09.2017

Financial or other Competing Interests: None.

Date of Publication : 19.12.2017 